\title{
Increased secondary nucleation underlies accelerated aggregation of the four-residue N-terminally truncated Aß42 species Aß5-42
}

Tanja Weiffert ${ }^{\mathrm{a}}$, Georg Meisl ${ }^{\mathrm{a}, \mathrm{c}}$, Patrick Flagmeier ${ }^{\mathrm{b}, \mathrm{c}}$, Suman $\mathrm{De}^{\mathrm{c}}$, Christopher J R Dunning ${ }^{\mathrm{a}}$, Birgitta

Frohm $^{\text {a }}$, Henrik Zetterberg ${ }^{\mathrm{d}, \mathrm{e}, \mathrm{f}, \mathrm{g}}$, Kaj Blennow ${ }^{\mathrm{d}, \mathrm{e}}$, Erik Portelius ${ }^{\mathrm{d}, \mathrm{e}}$, David Klenerman ${ }^{\mathrm{b}, \mathrm{c}, \mathrm{h}}$, Christopher Dobson $^{\mathrm{b}, \mathrm{c}}$, Tuomas Knowles ${ }^{\mathrm{b}, \mathrm{c}, \mathrm{i}}$, Sara Linse ${ }^{\mathrm{a}, *}$

${ }^{a}$ Department of Biochemistry and Structural Biology, Lund University, P O box 124, 22100 Lund, Sweden.

${ }^{\mathrm{b}}$ Centre for Misfolding Disease, Department of Chemistry, Cambridge University, Lensfield Road, Cambridge, CB2 1EW, United Kingdom.

${ }^{\mathrm{c}}$ Department of Chemistry, Cambridge University, Lensfield Road, Cambridge, CB2 1EW, United Kingdom

${ }^{\mathrm{d}}$ Institute of Neuroscience and Physiology, Department of Psychiatry and Neurochemistry, the Sahlgrenska Academy at the University of Gothenburg, Mölndal, Sweden

${ }^{\mathrm{e}}$ Clinical Neurochemistry Laboratory, Sahlgrenska University Hospital, Mölndal, Sweden

${ }^{\mathrm{f}}$ Department of Neurodegenerative Disease, UCL Institute of Neurology, Queen Square, WC1N London, United Kingdom

g UK Dementia Research Institute, WC1N London, United Kingdom

${ }^{\mathrm{h}}$ UK Dementia Research Institute, University of Cambridge, Cambridge CB2 0XY, United Kingdom

${ }^{i}$ Department of Physics, Cavendish Laboratory, University of Cambridge, Cambridge CB3 OHE, United Kingdom

Corresponding author: Sara Linse, Department of Biochemistry and Structural Biology, Lund University, P O box 124, 22100 Lund, Sweden, +46 46222 8246, sara.linse @ biochemistry.lu.se.

Keywords: misfolding, aggregation mechanism, toxicity, coaggregation, Alzheimer, BACE

\begin{abstract}
Aggregation of the amyloid- $\beta(\mathrm{A} \beta)$ peptide into plaques is believed to play a crucial role in Alzheimer's disease. Amyloid plaques consist of fibrils of full length $\mathrm{A} \beta$ peptides as well as $\mathrm{N}$-terminally truncated species. $\beta$-Site amyloid precursor protein-cleaving enzyme (BACE1) cleaves amyloid precursor protein in the first step in $A \beta$ peptide production and is an attractive therapeutic target to limit $A \beta$ generation.
\end{abstract}


Inhibition of BACE1, however, induces a unique pattern of $A \beta$ peptides with increased levels of $\mathrm{N}$ terminally truncated $\mathrm{A} \beta$ peptides starting at position $5(\mathrm{~A} \beta 5-\mathrm{X})$, indicating that these peptides are generated through a BACE1-independent pathway. Here we elucidate the aggregation mechanism of $\mathrm{A} \beta 5-42$ and its influence on full-length $\mathrm{A} \beta 42$. We find that, compared to $A \beta 42, A \beta 5-42$ is more aggregation prone and displays enhanced nucleation rates. A $35-42$ oligomers cause non-specific membrane disruption to similar extent as $\mathrm{A} \beta 42$ but appear at earlier time points in the aggregation reaction. Noteworthy, this implies similar toxicity of $A \beta 42$ and $A \beta 5-42$ and the toxic species are generated faster by A $\beta 5-42$. The increased rate of secondary nucleation on the surface of existing fibrils originates from a higher affinity of $\mathrm{A} \beta 5-42$ monomers for fibrils, as compared to $A \beta 42$ : an effect that may be related to the reduced net charge of $A \beta 5-42$. Moreover, $A \beta 5-42$ and $A \beta 42$ peptides coaggregate into heteromolecular fibrils and either species can elongate existing $\mathrm{A} \beta 42$ or $\mathrm{A} \beta 5-42$ fibrils but $\mathrm{A} \beta 42$ fibrils are more catalytic than A $\beta 5-42$ fibrils. Our findings highlight the importance of the N-terminus for surface-catalyzed nucleation and thus the production of toxic oligomers. 


\section{Introduction}

Alzheimer's disease (AD) is an increasingly common neurodegenerative disorder characterized by the presence of extracellular plaques composed of amyloid- $\beta(A \beta)$ fibrils surrounded by dystrophic neurites, intracellular neurofibrillary tangles composed of hyperphosphorylated aggregated tau protein, accompanied by synaptic and neuronal degeneration (1). The amyloid cascade hypothesis postulates that there is an imbalance in the production and clearance of the $\mathrm{A} \beta$ peptides and that the formation of neurotoxic $A \beta$ oligomers and accumulation of $A \beta$ triggers AD pathology (2). Several $A \beta$ variants differing in the $\mathrm{N}$ - and $\mathrm{C}$-termini are present in the brains of individuals suffering from $\mathrm{AD}$ and it has been reported that over $60 \%$ of the $\mathrm{A} \beta$ load consists of $\mathrm{N}$-terminally truncated peptides (3).

In vivo, $\mathrm{A} \beta$ peptides are generated by proteolysis from the larger transmembrane amyloid precursor protein (APP). In the amyloidogenic pathway, A $\beta$ cleavage before Asp- 1 is catalyzed by $\beta$-site APPcleaving enzyme 1 (BACE1). Subsequently, $\gamma$-secretase cleaves the membrane/spanning part of APP resulting in peptides with a variety of C-terminal lengths (reviewed in (4)). With the aim to reduce the A $\beta$ load in the brain several pharmaceutical companies have developed drugs that are aimed at having disease-modifying effects and one of the top candidates is inhibition of BACE1 (5). It has been shown that inhibition of BACE1 leads to alterations in the $\mathrm{A} \beta$ peptide pattern resulting in decreased levels of $A \beta 1-34, A \beta 1-40$ and $A \beta 1-42$ and increased levels of $A \beta 5-40$ (6). The fact that $A \beta$ peptides starting at position 5 are generated in spite of $\mathrm{BACE} 1$ inhibition indicates that $\mathrm{A} \beta 5-\mathrm{X}$ is most likely generated in a BACE1-independent APP-processing pathway in humans and that this pathway is upregulated in response to BACE1 inhibition in a dose-dependent manner (7). The neurotoxic effects of A $\beta 5-\mathrm{X}$ remain to be elucidated and are likely to be important for therapeutic approaches aiming at BACE1 inhibition.

The aggregation propensity varies between different $A \beta$ species $(8,9)$. Their coexistence in vivo makes it important to determine the aggregation mechanism for each peptide and investigate the influence of each $A \beta$ variant on coexisting species. The aggregation kinetics of $A \beta$ vary strongly with peptide concentration in a highly predictable manner (10). Reproducible experimental data together with theoretical analysis applying the rate laws derived for the fibril assembly process (11) have led to 
elucidation of the aggregation mechanisms for several $A \beta$ species $(8,12,13)$. $A \beta$ oligomers and fibrils are formed through a nucleated growth process where initial aggregates are formed from soluble peptides by primary nucleation. The addition of monomeric peptides to the initial aggregates results in elongation and thus fibril growth. New fibrils are also generated through secondary processes, such as fragmentation and secondary nucleation. Fragmentation occurs under certain conditions, e.g., at low ionic strength of the surrounding environment (14). Secondary nucleation, where the formation of new nuclei is catalyzed by existing fibrils, has been shown to be very important for various $A \beta$ species ( 8 , $12,13)$. Primary nucleation is a slow process compared to secondary nucleation and the formation of the majority of new aggregates is catalyzed by existing fibrils in vitro $(8,12)$. N-terminally truncated $A \beta$ species has been shown to aggregate faster than full length $A \beta$ while exhibiting a similar extent of neurotoxicity to full-length $\mathrm{A} \beta$ (15). Furthermore, it has been suggested that N-terminally truncated forms of the $A \beta$ peptide could initiate or nucleate the aggregation procedure resulting in pathological $\mathrm{A} \beta$ assemblies (15).

Fibrils formed from peptide species of one length may catalyze the formation of new fibrils from peptide species of a different length. It is therefore of great importance to examine whether cross-catalysis and coaggregation of $A \beta$ peptides of different lengths can occur. The coaggregation behavior of mutant $A \beta$ species or $A \beta$ species varying in sequence length has been shown to differ depending on the specific $A \beta$ peptides species in the mixture $(9,16-18)$.

Here, we elucidate the aggregation mechanism of A $\beta 5-42$ combining highly reproducible experimental measurements for the aggregation kinetics with a detailed theoretical analysis that enables global fitting of the measurements using rate laws derived through a master equation approach $(8,12)$, with an aim to unravel the relative importance of different microscopic steps involved in amyloid formation. Furthermore, we examine the self-seeding and cross-seeding capacities of A $35-42$ and $A \beta 42$ and whether the two species can coaggregate into heteromolecular fibrils. Finally, the $\mathrm{Ca}^{2+}$ influx into lipid vesicles caused by $A \beta 42$ and $A \beta 5-42$ is measured as an indication of the toxicity of the two peptides. 


\section{Results and Discussion}

In vivo, a complex mixture of $\mathrm{N}$-terminally and $\mathrm{C}$-terminally truncated and extended $\mathrm{A} \beta$ peptides coexist. Despite the identification of numerous different proteolytic fragments of APP, therapeutic targeting has been aimed at canonical forms of $\mathrm{A} \beta$. BACE1 has long been considered the primary target for reducing the $\mathrm{A} \beta$ load in individuals suffering from $\mathrm{AD}$ (5), although a series of large Phase III trials evaluating different BACE1 inhibitors on patients in different clinical stages have been arrested due to lack of efficacy or unfavorable risk/benefit ratio, see, e.g., reference (19). While it is well known that inhibition of BACE1 results in reduction of A $\beta$ peptides starting at position 1 (20) it has previously been shown that the levels of $\mathrm{N}$-terminally truncated $\mathrm{A} \beta 5-\mathrm{X}$ and $\mathrm{N}$-terminally extended $\mathrm{A} \beta$ forms increase (21).

\section{Concentration dependence of Aß5-42 aggregation}

The aggregation propensity of $\mathrm{A} \beta 5-42$ was investigated by monitoring changes in ThT fluorescence over time for a significant number of individual experiments under quiescent conditions as previously described (22). To remove preformed small aggregates, if any, the peptide samples were subjected to size exclusion chromatography just before the aggregation reaction. In the concentration ranges of the $\mathrm{A} \beta$ peptides and ThT used in this study, the fluorescence intensity scaled linearly with the fibril mass and ThT did not affect the aggregation of the A $\beta$ species (Supporting Information, Fig. S1 and (12)).

The aggregation experiments, performed at initial monomer concentrations $\left(\mathrm{m}_{0}\right)$ ranging from 0.125 to $5 \mu \mathrm{M}$, showed an overall accelerated aggregation rate of A $\beta 5-42$ compared to $\mathrm{A} \beta 42$ (Fig. 1A). The halftime $\left(t_{1 / 2}\right)$ of the aggregation reaction, which is the time point when half of the peptide in solution is aggregated, was estimated by fitting a sigmoidal function to every curve. The monomer dependence of $t_{1 / 2}$ is described by the scaling exponent, $\gamma$, where $t_{1 / 2} \approx \mathrm{m}_{0}^{\gamma}$ (Fig. 1B), which provides a first indication as to which nucleation mechanism is likely to dominate the aggregation process. For $A \beta 5-42$, the scaling exponent was $-0.9 \pm 0.07$, which is higher than the scaling exponent for $\mathrm{A} \beta 42$, thus the concentration dependence is less steep for $A \beta 5-42$ than for $A \beta 42$ (12). Some deviation from a power function was seen and at higher protein concentrations $(>2.5 \mu \mathrm{M})$ the scaling exponent appeared to increase (i.e., less 
negative value). The concentration dependence of the scaling exponent indicates that one or more of the microscopic steps involved in the aggregation process become saturated at high monomer concentrations.

A

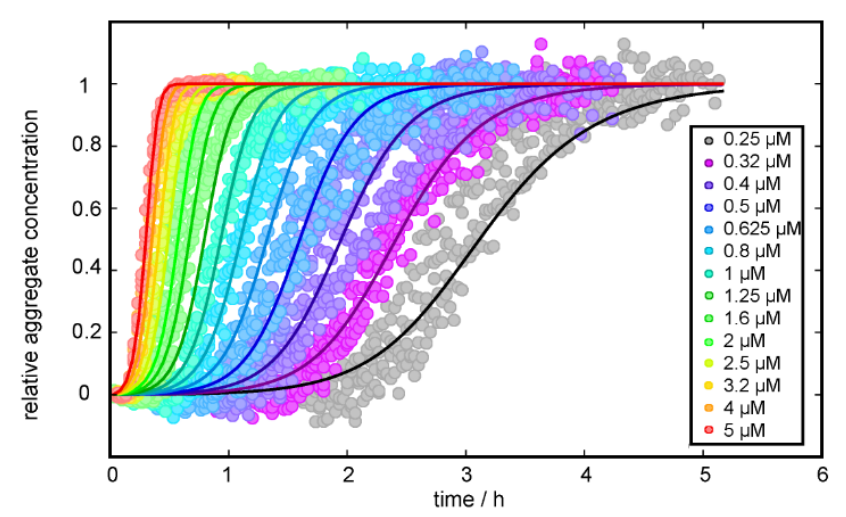

C

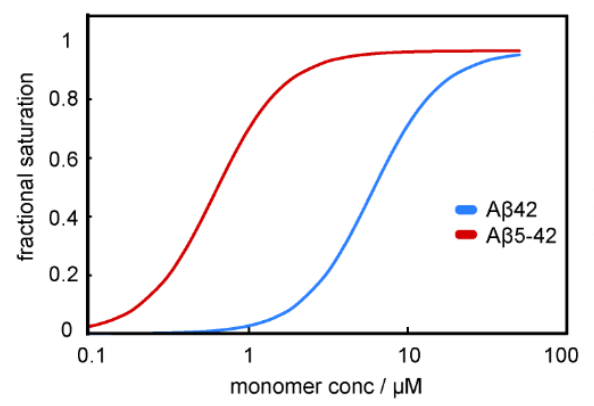

B

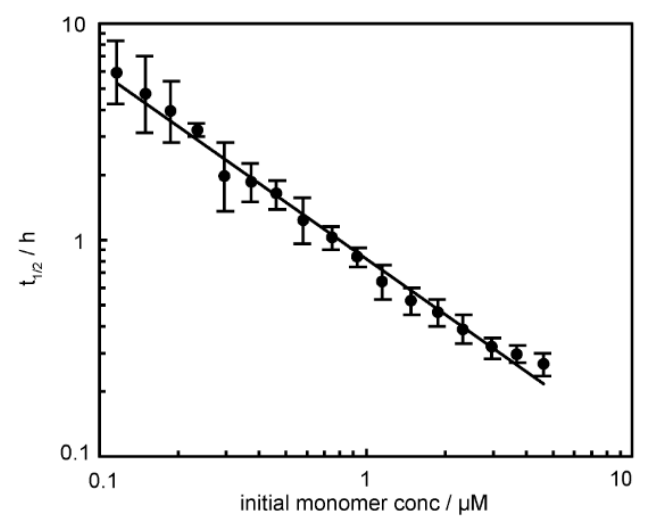

E

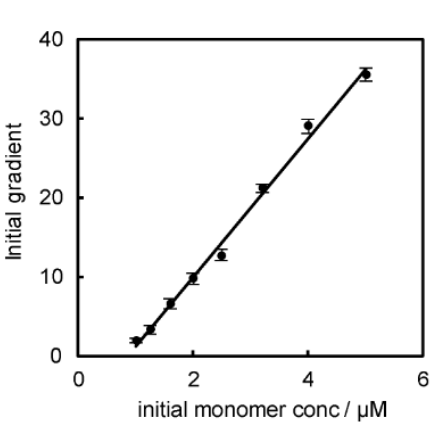

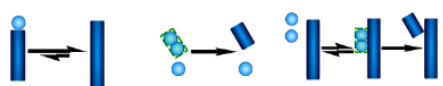

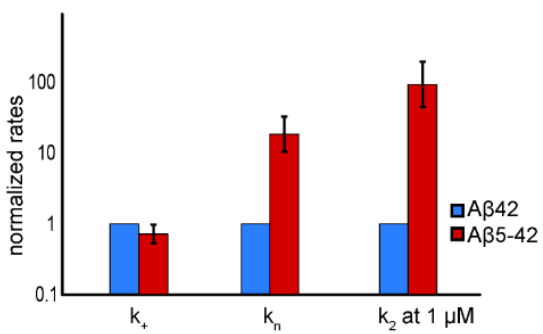

Fig. 1. Aggregation kinetics of Aß5-42. (A) Aggregation of A $\beta 5-42$ over time. Experimental data are shown as circles and the global fit is shown as lines. The global fit to the experimental data for $A \beta 5-42$ contained three free parameters: $K_{M}$ and the combined rate constants $k_{+} k_{n}$ and $k_{+} k_{2}$. Data points at lower peptide concentration were removed for clarity, all concentrations can be seen in Supporting information Fig. S2. (B) Half-time of fibril formation as a function of initial monomer concentration on double logarithmic axes. Error bars were obtained from the standard deviation from three experiments with four replicates in each experiment. The slope of the fitted line gives the scaling exponent, $\gamma=-0.9 \pm 0.07$, obtained from three repeats of the aggregation experiments. (C) The predicted saturation of fibrils in surface-bound species for both $\mathrm{A} \beta 42$ (blue) and $\mathrm{A} \beta 5-42$ (red). Note that in the range of sampled concentrations, $A \beta 5-42$ is significantly more saturated, explaining the observed increased secondary 
nucleation rate compared to $A \beta 42$. (D) Initial gradient of the ThT fluorescence curves from strongly seeded aggregation experiments as a function of initial monomer concentration. Error bars were obtained from the standard deviation of three replicates. The linear relationships imply that the elongation rate is not saturated. (E) Comparison of the rate constants obtained from the global fitting to the kinetic data displayed relative to the rates for $\mathrm{A} \beta 42$ on a logarithmic axis, underneath the schematic depiction of the respective reaction step. Error bars were obtained from standard deviation of repeats of the aggregation experiments as well as the errors in the estimation of the average fibril length required to obtain the elongation rate constant.

\section{Kinetic analysis}

To obtain further insight into the rate constants of the microscopic steps involved in the aggregation process, the kinetic traces for A $\beta 5-42$ were fitted globally using the Amylofit platform (23). All kinetic curves were fitted by the same rate constants and reaction orders and from the fit the combined rate constants, $k_{+} k_{n}$ and $k_{+} k_{2}$ (where $k_{n}$ is the primary nucleation rate constant, $k_{+}$is the elongation rate constant and $\mathrm{k}_{2}$ is the secondary nucleation rate constant) were obtained (Supporting Information Table S1). The best description of the experimental measurements was generated by globally fitting all kinetic data, at all concentrations, using a single rate law (Eq. 2) describing a multi-step secondary nucleation process (Fig. 1A). Models that exclude secondary nucleation are not able to describe the experimental measurements of the aggregation. Fits using alternative models are shown in Supporting information

Fig. S3. The model that describes the data explicitly treats secondary nucleation as a multi-step event where initial attachment of monomers or preformed oligomers to fibrils is followed by formation and detachment of a new nucleus. At high concentrations of monomeric peptides, the surfaces of existing fibrils become fully covered and the secondary nucleation rate becomes independent of the monomer concentration and limited by the formation and detachment of newly formed nuclei. This saturation of the secondary nucleation rate is accounted for by the Michaelis constant for saturation of secondary nucleation, $\mathrm{K}_{\mathrm{M}}$ (Fig. 1C). The requirement of a multistep secondary nucleation model to globally fit the data indicates that the secondary nucleation rate is limited by the monomer-dependent step at low monomer concentrations, while at high monomer concentrations the secondary nucleation rate is limited 
by the monomer-independent step, i.e., the rearrangement/detachment step of the newly formed nuclei. This two-step model, that results in Michaelis-Menten-like saturation kinetics, can account for the variation in scaling exponent observed in the half time analysis (Fig. 1B).

\section{Seeded aggregation kinetics}

Next, we carried out experiments in which we modified the aggregation process by the addition of preformed seeds to investigate whether the elongation rate was saturated within the investigated regime. Preformed fibrils were added to monomers at such high concentrations (at least $30 \%$ seeds) that the nucleation processes are negligible, and the aggregation reaction is dominated by the elongation of already existing fibrils. These experiments showed that the initial slopes of the kinetic profiles scaled linearly with the initial monomer concentration, which is an indication that the elongation rate is not saturated within the studied concentration regime (Fig. 1D).

Strongly seeded aggregation experiments were used to estimate the elongation rate constant, $\mathrm{k}_{+}$, by measuring the initial increase in aggregate mass through fitting a linear slope to the early time-points of the aggregation process (Fig. 1D) $(8,24)$. The initial aggregation behavior at high seed concentrations is only dependent on the elongation of already existing fibrils and the nucleation processes become negligible. In order to estimate the elongation rate constant, the number of seed fibrils was determined by measuring the average length of fibrils in cryo-TEM images. Once the elongation rate constant was determined the combined rate constants, $\mathrm{k}_{+} \mathrm{k}_{\mathrm{n}}$ and $\mathrm{k}_{+} \mathrm{k}_{2}$, from the global fit, could be decomposed into individual rate constants. However, these individual rate constants are less accurate than the combined rate constants due to the approximations involved in calculating the average number of monomers per fibril from cryo-TEM images. We note that, the elongation rate constant of A $\beta 5-42$ is very similar to the previously reported elongation rate constant for $A \beta 42$ (12). Thus, the increased aggregation rate of $A \beta 5$ 42 compared to $\mathrm{A} \beta 42$ is likely to be due to accelerated primary nucleation and secondary nucleation processes (Fig. 1E).

At low concentrations of seeds, the direct elongation contributes negligibly to the overall fibril mass. However, the lag-time was shortened by addition of preformed fibrils since the slow primary nucleation 
step can be bypassed and secondary nucleation, that is catalyzed by the seeds, can occur immediately. Furthermore, the kinetics of the seeded experiments can be predicted from the rate constants obtained from the unseeded experiments, further supporting the presence of a multi-step secondary nucleation mechanism in the aggregation process of the $A \beta 5-42$ peptides.

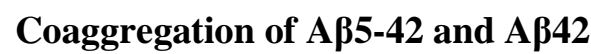

In addition to determining the aggregation mechanism for each $A \beta$ species, it is of key relevance for the in vivo situation to find out how the aggregation process of one $\mathrm{A} \beta$ species affects the aggregation mechanism of coexisting $A \beta$ species.

Coaggregation of $A \beta 42$ and $A \beta 5-42$ was studied for heteromolecular mixtures of monomeric peptides at equimolar concentrations. Each aggregation curve was found to display a single sigmoidal transition, indicating that the two species undergo coaggregation (Fig. 2A). We have previously shown that mixtures of $A \beta$ peptides that do not form coaggregates, e.g., mixtures of $A \beta 40$ and $A \beta 42$, produce biphasic aggregation curves (16), whereas mixtures of $\mathrm{A} \beta$ peptides that do form coaggregates, e.g., mixtures of $\mathrm{A} \beta 42$ and $\mathrm{N}$-terminally extended $\mathrm{A} \beta 42$, display single sigmoidal transitions with reduced ThT intensity (9). We study the coaggregation using a 1:1 molar ratio since the probability of experimentally detecting coaggregation is greatest under this condition, although in vivo the ratio between $A \beta 5-42$ and $A \beta 42$ is most likely below 1:1.

There was no detectable aggregation for 1:1 mixture below a total concentration of $2 \mu \mathrm{M} A \beta$, although aggregation of each peptide alone is observed well below $1 \mu \mathrm{M}$. The ThT fluorescence signal intensity was lower for fibrils formed from mixed samples than for those formed from the individual species and the ThT signal intensity was therefore too low to investigate the aggregation behavior of $A \beta$ mixtures at concentrations below $2 \mu \mathrm{M}$. As shown in Fig. 2B, the sum of the individual ThT signals at the plateau for the aggregation of pure $A \beta 42$ and $A \beta 5-42$ is more than twice the signal obtained for the aggregation of the same concentrations of $A \beta 42$ and $A \beta 5-42$ together. In order to investigate if this decrease in signal was due to a decrease in the amount of aggregates present, rather than a change in fluorescence intensity per mole of aggregates, the fibrils were removed by centrifugation and the remaining monomers were 
analyzed by gel electrophoresis (Supporting information, Fig S4). Since no monomeric peptides could be detected on the gel, the remaining concentration of monomeric peptide after fibrillation was below the detection limit, approximately $1 \mu \mathrm{M}$. This indicates that the decrease in fluorescence intensity is due to differences in ThT binding to fibrils formed from mixed samples as compared to homomolecular samples. This finding further strengthens our conclusion that mixed fibrils are formed and thus that $\mathrm{A} \beta 42$ monomers have the ability to elongate $\mathrm{A} \beta 5-42$ fibrils and vice versa.

The half-times of aggregation for mixtures at varying concentrations were compared with the half-times of the aggregation of homomolecular $A \beta 42$ and $A \beta 5-42$ (Fig. 2C). The behavior of the aggregation rate of the mixture differs from the aggregation rate of the individual species. At low concentrations of the mixture of $A \beta 42$ and $A \beta 5-42$, the aggregation rate was similar to the overall aggregation rate of $A \beta 42$, while at higher concentrations the rate was similar to the overall aggregation rate of $A \beta 5-42$. Thus, the behavior of the mixtures of monomeric $\mathrm{A} \beta 5-42$ and $\mathrm{A} \beta 42$ is concentration dependent, indicating different effects on the microscopic steps of the aggregation process.

A

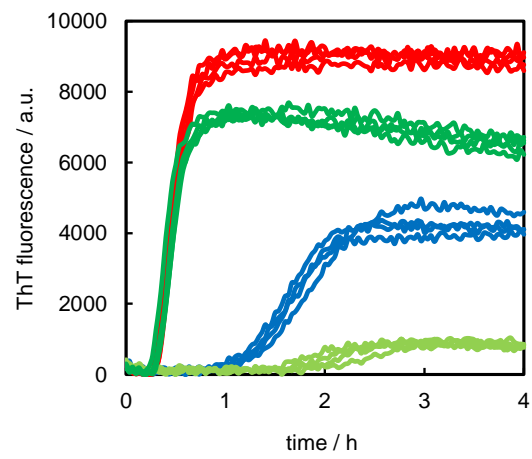

B

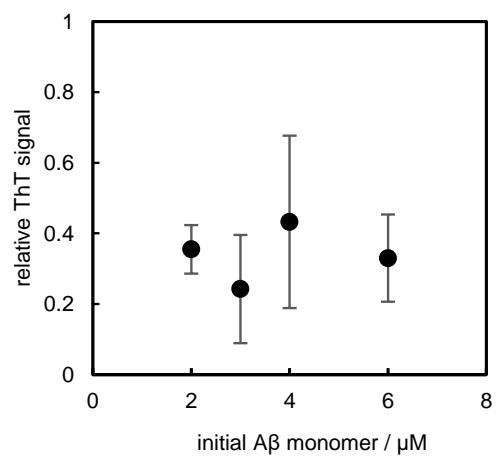

C

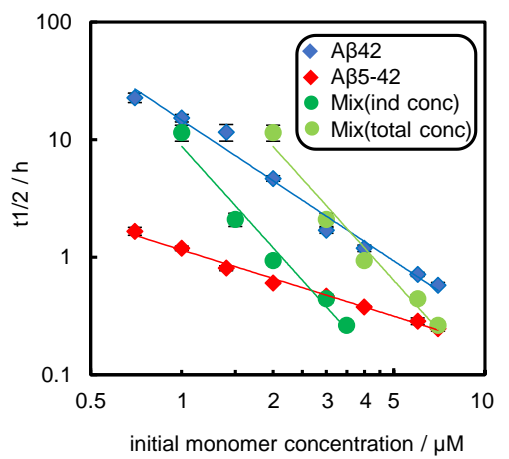

Fig. 2. Coaggregation of Aß42 and Aß5-42. (A) Typical data for aggregation of $3 \mu \mathrm{M}$ A $\beta 42$ (blue), 3 $\mu \mathrm{M} \mathrm{A} \beta 5-42$ (red), $3 \mu \mathrm{M} \mathrm{A} \beta 42+3 \mu \mathrm{M} \mathrm{A} \beta 5-42$ (dark green) and $1.5 \mu \mathrm{M} \mathrm{A} \beta 42+1.5 \mu \mathrm{M}$ A $\beta 5-42$ (light green). (B) Relative ThT intensity obtained at the plateau from the coaggregated $\mathrm{A} \beta 42$ and $\mathrm{A} \beta 5-42$ mixture to that of the sum of the individual ThT intensities. Error bars were obtained from three experiments with four technical repeats. (C) Half-times of aggregation for varying concentrations of $\mathrm{A} \beta 42$ (blue), $\mathrm{A} \beta 5-42$ (red), individual concentrations of equimolar mixtures of $\mathrm{A} \beta 42$ and $\mathrm{A} \beta 5-42$ (dark 
green circles) and total concentrations of equimolar mixtures of $A \beta 42$ and $A \beta 5-42$ (light green circles).

Error bars were obtained from 4 repeats.

\section{Cross-catalysis of A $\mathrm{A} 42$ and $\mathrm{A} \beta 5-42$}

Experiments where preformed $A \beta 42$ fibrils were added to $A \beta 5-42$ monomers and preformed $A \beta 5-42$ fibrils were added to A $\beta 42$ monomers, reveal the cross-seeding capacity of the different fibrils (Fig. 3). We find that seeds consisting of both truncated and full-length peptides can accelerate the aggregation of the other species. However, seeds of $\mathrm{A} \beta 42$ caused a larger reduction of $\mathrm{t}_{1 / 2}$, i.e., the aggregation of both $\mathrm{A} \beta 42$ and $\mathrm{A} \beta 5-42$ monomers was accelerated more by the addition of $\mathrm{A} \beta 42$ seeds than by the addition of $A \beta 5-42$. Furthermore, higher $A \beta 5-42$ seed concentrations are required to significantly accelerate the aggregation process. This indicates that the $\mathrm{N}$-terminal segment of $\mathrm{A} \beta$ peptides in fibrils is involved in either elongation or secondary nucleation. Regardless of seed species the monomeric forms of $A \beta 5-42$ always aggregated faster than monomeric $A \beta 42$ at the same concentration of preformed seeds.
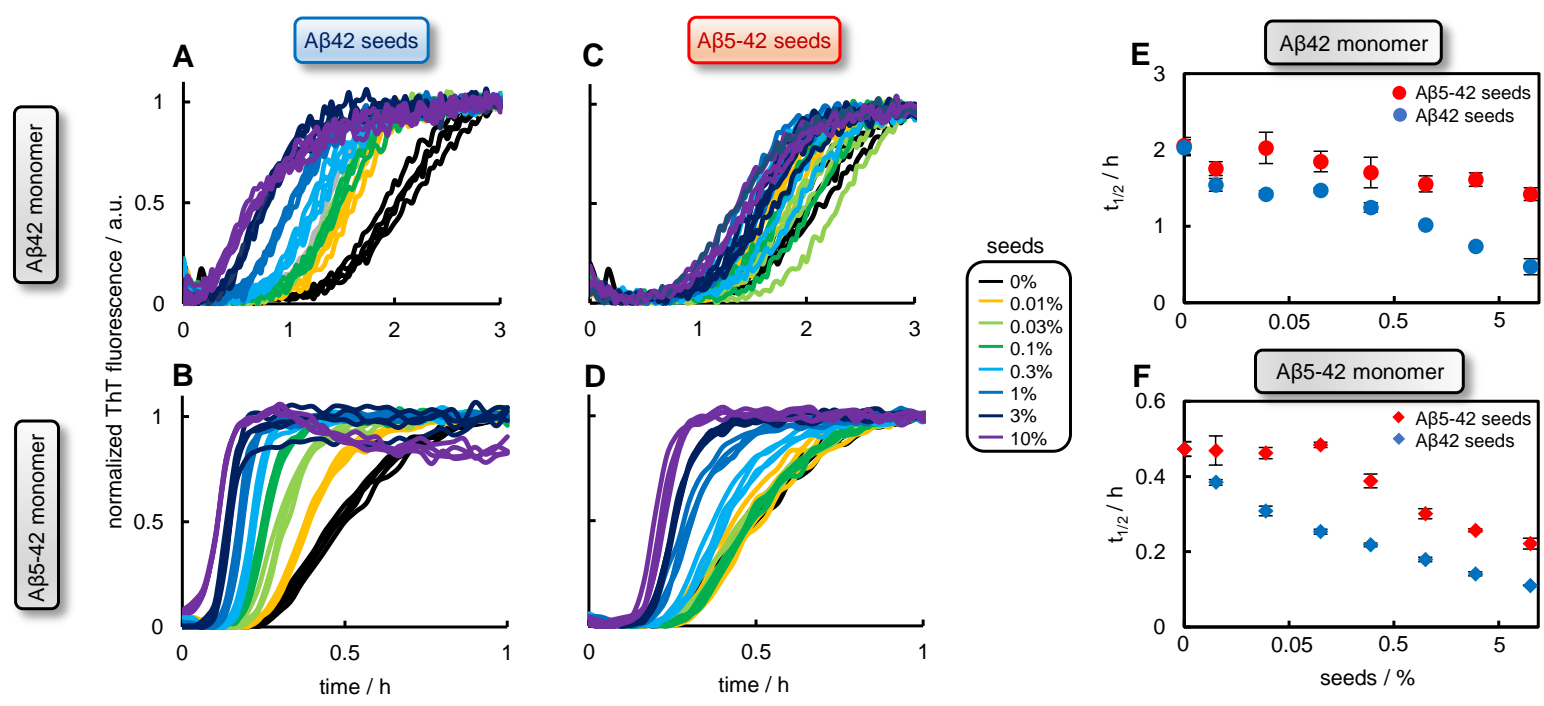

Fig. 3. Seeded aggregation kinetics of $\mathbf{A} \beta 42$ and $\mathbf{A} \beta 5-42$. Kinetic data for a representative experiment with four technical repeats for $2 \mu \mathrm{M} A \beta 42$ monomer with $\mathrm{A} \beta 42$ seeds (A), $2 \mu \mathrm{M}$ A $\beta 5-42$ monomer with 
$\mathrm{A} \beta 42$ seeds (B), $2 \mu \mathrm{M}$ A $\beta 42$ monomer with A $\beta 5-42$ seeds (C), $2 \mu \mathrm{M}$ A $\beta 5-42$ monomer with $\mathrm{A} \beta 5-42$ seeds (D). Half-times of A $\beta 42$ fibril formation as a function of added seeds with addition of $A \beta 42$ seeds shown in blue and addition of A $\beta 5-42$ seeds shown in red (E). Half-times of A $\beta 5-42$ fibril formation as a function of added seeds with addition of $A \beta 42$ seeds shown in blue and addition of $A \beta 5-42$ seeds shown in red (F). Non-normalized data is shown Supporting information Fig. S5.

A

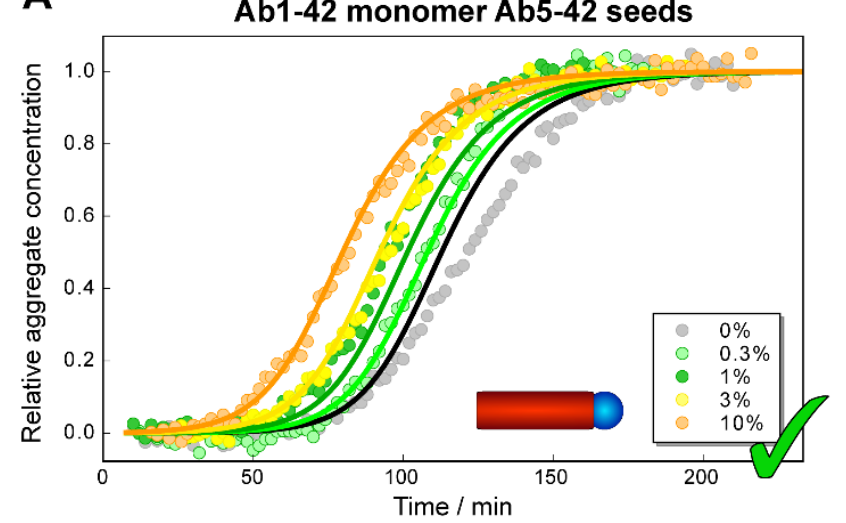

B

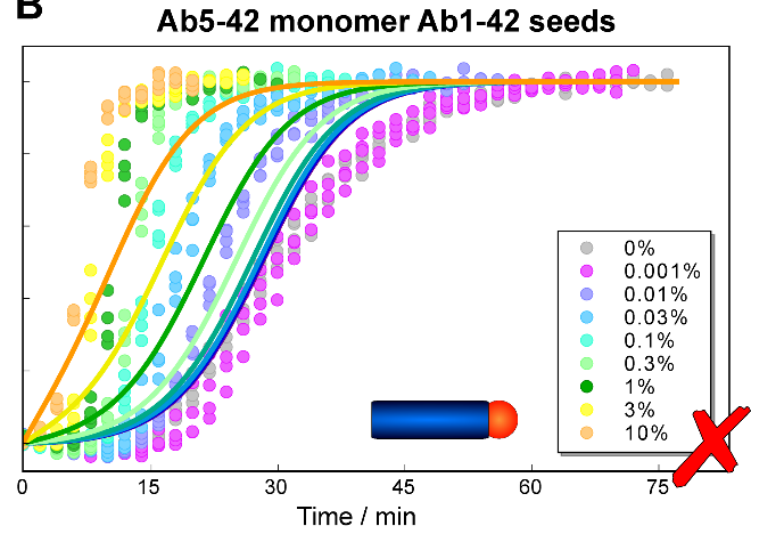

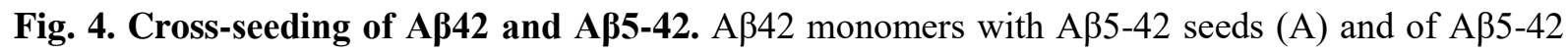
monomers with $\mathrm{A} \beta 42$ seeds (B) at a range of different seed concentrations. Median values are shown in A and all data points are shown in Supporting information Fig. S6. Seed concentrations below $0.3 \%$ are not shown in A as they show no significant difference from the unseeded case. The solid lines are fits to the data, using the rates from unseeded experiments and assuming that the seeds are simply elongated by the monomers to form fibrils that behave the same way as those formed in the absence of seeds. While the data in A are consistent with this model, the data in B are not and require a more complex mechanism for achieving and acceptable fit.

Using the rates obtained for the unseeded aggregation of monomeric peptides, we further investigated the effect of cross-seeding. The minimal assumption, based on the observation of mixed fibrils in the coaggregation experiments, is that seeds of one species can be elongated through the addition of monomeric peptides of the other species. The effect of $A \beta 5-42$ seeds on $A \beta 42$ aggregation is consistent 
with this minimal assumption, i.e., an elongation of $\mathrm{A} \beta 5-42$ seeds by $\mathrm{A} \beta 42$ monomers, at a rate much slower than for elongation of $\mathrm{A} \beta 42$ seeds, is sufficient to explain the observed behavior (Fig. 4A). By contrast, the effect of $A \beta 42$ seeds on $A \beta 5-42$ aggregation cannot be explained with this simple model (Fig. 4B). Most notably, the slope of the aggregation curves, determined by the elongation and secondary nucleation rates of the growing fibrils, increases with increasing $A \beta 42$ seed amount. This observation indicates that the fibrils formed from $\mathrm{A} \beta 5-42$ monomers, in the presence of $0.1 \%$ or more of A $\beta 42$ seeds, differ significantly from those formed from pure A $35-42$ monomer. Fits using different models trying to describe this behavior are shown in Supporting information Fig. S7-8. The fact that the slope of the aggregation curves increases continuously as the seed concentration is increased, as reflected by the increase in $\mathrm{k}_{2}$ when fitted to the curves individually (Fig. S8), implies that the A $\beta 42$ seeds induce the formation of a new type of A $\beta 5-42$ fibrils, which are not formed directly from A $\beta 5-42$ monomers and have a higher propensity to self-replicate. Cryo-TEM images reveal that fibrils formed from $A \beta 5-42$ monomers and $A \beta 42$ seed fibrils have reduced tendency to form large assemblies compared to A $\beta 5-42$ and $A \beta 5-42$ seeds (Fig. 5). Thus, the accessible surface area may be larger for fibrils formed in the presence of $\mathrm{A} \beta 42$ seeds which may contribute to the higher apparent $\mathrm{k}_{2}$ (Fig. S8).

\section{Morphology of aggregates}

Cryo transmission electron microscopy (cryo-TEM) was used to study aggregates of A $\beta 5-42, \mathrm{~A} \beta 5-42$ seeded with preformed A $\beta 5-42$ fibrils, $A \beta 5-42$ seeded with preformed $A \beta 42$ seeds, $A \beta 42$ seeded with preformed $A \beta 5-42$ seeds, $A \beta 42$ seeded with preformed $A \beta 42$ seeds and coaggregates of $A \beta 5-42$ and A $\beta 42$ (Fig. 5). The fibril length and twist distance varied in all samples, however, the average length of fibrils produced from unseeded $A \beta 5-42$ was shorter than those from unseeded $A \beta 42$. The average length of $\mathrm{A} \beta 5-42$ fibrils is $320 \mathrm{~nm}(\mathrm{SEM}=19, \mathrm{n}=116)$ and of $\mathrm{A} \beta 42$ fibrils is $760 \mathrm{~nm}(\mathrm{SEM}=46, \mathrm{n}=91)$, i.e. the ratio is 2.2. This ratio serves to verify the accuracy of the obtained rate constants in an independent measurement. Our model predicts the average fibril length to depend on the rate constants via

$$
\mu_{0} \approx \frac{2 k_{+} m_{0}}{\kappa}=\sqrt{\frac{2 k_{+}\left(1+m_{0}^{n_{2}} / K_{M}\right)}{k_{2} m_{0}^{n_{2}-1}}}
$$


Using the values of the rate constants for $A \beta 5-42$ determined here and those for $A \beta 42$ determined in Cohen et al. (12) (assuming a secondary nucleation Michaelis constant of $6 \mu \mathrm{M}$ for A $\beta 42$ ) we obtain a ratio of lengths of 2.6, in good agreement with our experimental observations.
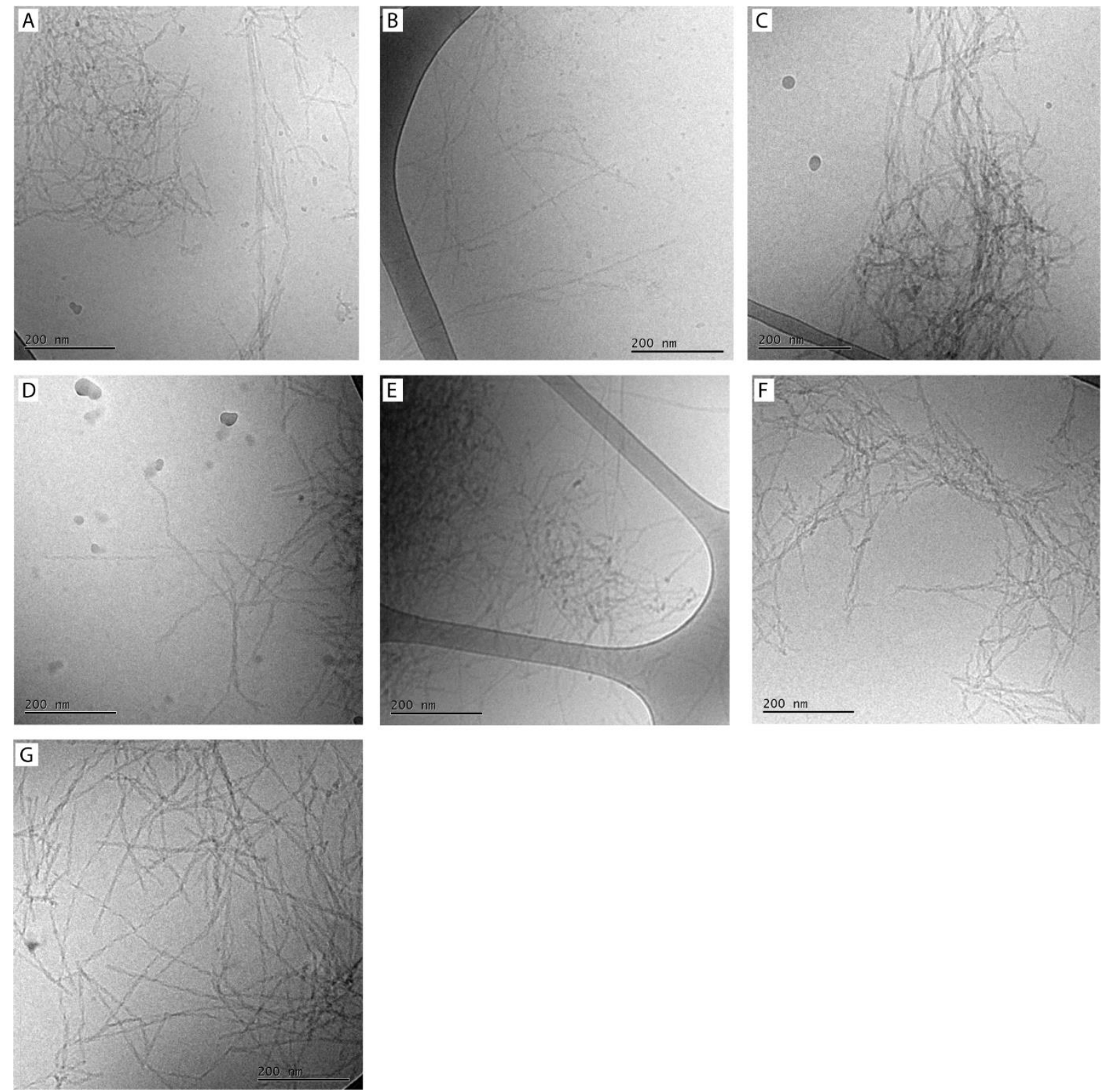

Fig. 5. Morphology of A $\boldsymbol{\beta}$ fibrils. Cryo-TEM images of the end-state of reactions for samples initially composed of A $\beta 5-42$ monomers (A), A $\beta 42$ monomers (B), A $\beta 5-42$ monomers seeded with $A \beta 5-42$ fibrils (C), $A \beta 5-42$ monomers seeded with $A \beta 42$ fibrils (D), $A \beta 42$ monomers seeded with $A \beta 5-42$ fibrils 
(E), $A \beta 42$ monomers seeded with $A \beta 42$ fibrils $(F)$ and an equimolar mixture of $A \beta 5-42$ and $A \beta 42$ monomers $(G)$.

\section{Effects of $\mathrm{N}$-terminal truncation on the aggregation process}

Kinetic experiments in combination with theoretical analysis have shown that $A \beta 42$ aggregation is dominated by autocatalytic secondary nucleation under quiescent conditions (12). We show that the overall aggregation rate of $A \beta 5-42$ is significantly faster than for full-length $A \beta 42$ under the same conditions. A global kinetic analysis allows us to translate the change in macroscopic aggregation behavior into the effects on the individual rate constants for primary nucleation, secondary nucleation and elongation. This analysis reveals a shift toward a mechanism where more fibrils are generated via a fibril-catalyzed nucleation reaction, a pathway that generates potentially toxic oligomers. Furthermore, we find that the elongation rate constants do not notably differ between $A \beta 42$ and $A \beta 5-42$, but the rate constant of primary nucleation is significantly higher for A $\beta 5-42$. As secondary nucleation saturates for $\mathrm{A} \beta 5-42$ in the sampled concentration range, whereas it does not for $\mathrm{A} \beta 42$, a direct comparison of secondary nucleation rate constants is not useful. Instead we consider the physical rate of formation of secondary nuclei, rather than just the rate constants, under representative conditions, at one monomer concentration. The relative predicted rates of secondary nuclei formation at $10 \%$ conversion of an initially monomeric sample at a concentration of $1 \mu \mathrm{M}$ are shown in Fig. 1E, where A $\beta 5-42$ has a significantly increased rate of secondary nuclei generation (by a factor of 100).

As secondary nucleation is a multi-step process, with an initial attachment step, followed by a conversion/detachment step, one may ask the question which part of the multi-step mechanism is affected the most by the deletion of four N-terminal residues. Our result show one aspect that clearly contributes to the increased rate of secondary nucleation: the increased saturation of fibrils by surfacebound $A \beta 5-42$, compared to $A \beta 42$ at the same concentration. The Michaelis constant of secondary nucleation, which determines the concentration at which the reaction is half saturated, was found to be $\sqrt{K_{M}} \sim 0.6 \mu \mathrm{M}$ for $\mathrm{A} \beta 5-42$, whereas a lower bound for $\mathrm{K}_{\mathrm{M}}$ in $\mathrm{A} \beta 42$ was previously estimated as $\sqrt{K_{M}}$ $>6 \mu \mathrm{M}$ (this lower bound is used to estimate and compare the coverage of the two peptides in Fig. 1C) 
(8). The second part of the process, the conversion/detachment step, is governed by the rate constant $\mathrm{k}_{2} \cdot \mathrm{K}_{\mathrm{M}}$, which was found to be $1.2 \pm 0.3 \cdot 10^{-6} \mathrm{~s}^{-1}$ for $\mathrm{A} \beta 5-42$ and can be estimated for $\mathrm{A} \beta 42$ using the above lower bound as $>0.4 \cdot 10^{-6} \mathrm{~s}^{-1}$. Thus, the conversion rate for A $\beta 5-42$ is comparable to the lower bound for the conversion rate of $\mathrm{A} \beta 42$ (within a factor of 3) and the increase in the overall rate of secondary nucleation is dominated by an increased attachment rate of A $35-42$. The comparable conversion rates of the $A \beta 42$ and $A \beta 5-42$ suggests that no important interactions are formed by the $\mathrm{N}$ terminus during the conversion step. Neither does the $\mathrm{N}$-terminal truncation appear to have any effect on the elongation rate implying that the transition state for elongation is similar for $A \beta 42$ and $A \beta 5-42$. By contrast, $\mathrm{N}$-terminal extensions have been shown to reduce the elongation rate (9).

\section{The origin of the effects}

$\mathrm{A} \beta 42$ has a net charge between -3 and -4 at neutral $\mathrm{pH}$ with the charged amino acid residues located in the N-terminal or middle part of the protein. Two of the four removed amino acids in A $\beta 5-42$ are negatively charged (Asp-1 and Glu-3), resulting in ca. two units less negative net charge of the truncated A $35-42$ peptide compared to $A \beta 42$. This results in reduced electrostatic repulsion between the monomers and between the monomers and fibrils and can partly explain the enhanced aggregation of A $\beta 5-42$. It has been established in other studies that decreased repulsion between monomers and fibrils accelerates all microscopic aggregation steps and makes A $35-42$ more susceptible to saturation of secondary nucleation (14). The attachment rate of the charged monomers to the charged fibrils is likely to benefit more from the charge change than the conversion and detachment rates, explaining why saturation of secondary nucleation is reached at a lower concentration of $A \beta 5-42$ compared to $A \beta 42$. Modulation of the electrostatic repulsion between $A \beta 42$ peptides has been shown to greatly influence the aggregation behavior (14) and several of the familial mutations within the $\mathrm{A} \beta$ peptide, leading to early onset FAD, having lower net charge than $\mathrm{A} \beta 42$ and subsequently altered aggregation behavior (13). Similarly to A $\beta 5-42$, several of the familial A $\beta 42$ mutants with less negative charge have increased primary and secondary nucleation rates with the secondary nucleation rate becoming saturated and independent of monomer concentrations at high peptide concentrations (13). Another contributing factor to the rate enhancement comes from the shorter length of the non-amyloidogenic $\mathrm{N}$-terminus of $\mathrm{A} \beta 5$ - 
42. Hence, a general physicochemical effect involving increased frequency of productive molecular encounters for a shorter peptide may contribute to the increased primary and secondary nucleation rates of A $\beta 5-42$. This physicochemical effect has been shown to explain the progressive retardation of the aggregation upon $\mathrm{N}$-terminal extensions due to decreased probability of productive encounters for extended $A \beta 42$ peptides (9).

\section{Both Aß species cause membrane disruption}

Both $N$-terminally extended and truncated forms of $A \beta$ are shown to have neurotoxic effects $(15,25)$. It is generally believed that oligomeric species formed during the aggregation of $A \beta$ are the toxic species and several possible mechanisms generating the toxicity have been identified (reviewed in (26) and (27)). Specific binding of oligomers to receptors on cell membranes have been suggested to mediate toxicity as well as non-specific membrane disruption. Non-specific membrane disruption is believed to contribute to cellular damage making the cells permeable to $\mathrm{Ca}^{2+}$, resulting in $\mathrm{Ca}^{2+}$ influx and disruption of $\mathrm{Ca}^{2+}$ homeostasis (27-29).

We applied a highly sensitive method that quantitatively measures the extent of membrane disruption caused by protein aggregates by measuring the $\mathrm{Ca}^{2+}$ influx into lipid vesicles (30). This method has previously been used to study potentially toxic $A \beta 42$ aggregates (30). Lipid vesicles containing $\mathrm{Ca}^{2+}-$ sensitive fluorescent dye molecules were tethered to a passivated surface and the $\mathrm{Ca}^{2+}$ influx induced by $\mathrm{A} \beta 42$ or A $35-42$ into individual vesicles were measured by monitoring changes in the fluorescence intensity using total internal reflection fluorescence microscopy (TIRFM). The A $\beta$ samples were incubated at $37^{\circ} \mathrm{C}$ under quiescent conditions and the $\mathrm{Ca}^{2+}$ influx was measured for 3 repeats of aliquots removed from the samples at the start of the aggregation reaction $\left(t_{1}\right)$, at the end of the lag-phase $\left(t_{2}\right)$ and at the plateau phase $\left(t_{3}\right)$ (Fig. 6). For each experiment, the background fluorescence was measured before the $A \beta$ sample was added, and followed by addition of a cation transporting ionophore, ionomycin, which results in $\mathrm{Ca}^{2+}$ influx to saturation (Supporting information, Fig S9). This enabled calculation of the percentage of $\mathrm{Ca}^{2+}$ influx into each individual vesicle. The fluorescence intensity change was 
measured for at least 700 vesicles per sample and averaged (30). The addition of monomeric A $\beta 5-42$ or A $\beta 42$ caused no detectable increase in fluorescence. By addition of $A \beta$ aliquots taken from the end of the lag phase, $\mathrm{t}_{2}$ the fluorescence intensity within the vesicles increased due to $\mathrm{Ca}^{2+}$ influx. $\mathrm{A} \beta 5-42$ caused $\mathrm{Ca}^{2+}$ influx into the vesicles to the same extent as $\mathrm{A} \beta 42$. Aliquots removed from the aggregation reaction in the plateau phase for $\mathrm{A} \beta 42$ and $\mathrm{A} \beta 5-42\left(\mathrm{t}_{3}\right)$ caused lower $\mathrm{Ca}^{2+}$ influx compared to those aliquots removed at $t_{2}$, although higher than samples taken at $t_{1}$.

In summary, the extent of $\mathrm{Ca}^{2+}$ influx into vesicles, caused by the interaction of $\mathrm{A} \beta$ was comparable between $A \beta 42$ and $A \beta 5-42$ aliquots that were collected at the corresponding time-point during the aggregation process. Thus, the toxicity of the A $\beta 5-42$ variant is within the error limit the same as of A $\beta 42$ at equal peptide concentrations, i.e. within one standard deviation obtained from three independent measurements. A $\beta 42$ oligomers have previously been shown to exert increased toxicity compared to monomers and fibrils in cells (12). Oligomer-binding molecules have been shown to reduce the $\mathrm{Ca}^{2+}$ influx caused by $\mathrm{A} \beta 42$ species collected at $\mathrm{t}_{2}$ implying that oligomers are the cause of $\mathrm{Ca}^{2+}$ influx into the lipid vesicles (30). Toxicity is dependent on the number of oligomers and toxicity per oligomer, thus the similar toxicity of $A \beta 5-42$ and $A \beta 42$ may be due to formation of similar amounts of oligomers with similar toxicity. The hydrophobic C-terminus is likely the major contributor to membrane permeabilization and this part of the peptide is identical in $\mathrm{A} \beta 5-42$ and $\mathrm{A} \beta 42$, thus the toxicity per oligomer is most likely similar. These findings, that elucidate the features of early assembly of A $\beta$ species, are in line with previous studies which have shown that structural features of early oligomers of $\mathrm{A} \beta 42$ are most importantly controlled by the C-terminus while $\mathrm{N}$-terminal truncations have little effect (31-33). Importantly, the species causing $\mathrm{Ca}^{2+}$ influx into the lipid vesicles are formed much faster from $A \beta 5-42$ peptides than from $A \beta 42$ peptides at the same concentrations due to the higher secondary nucleation rate of $A \beta 5-42$. 

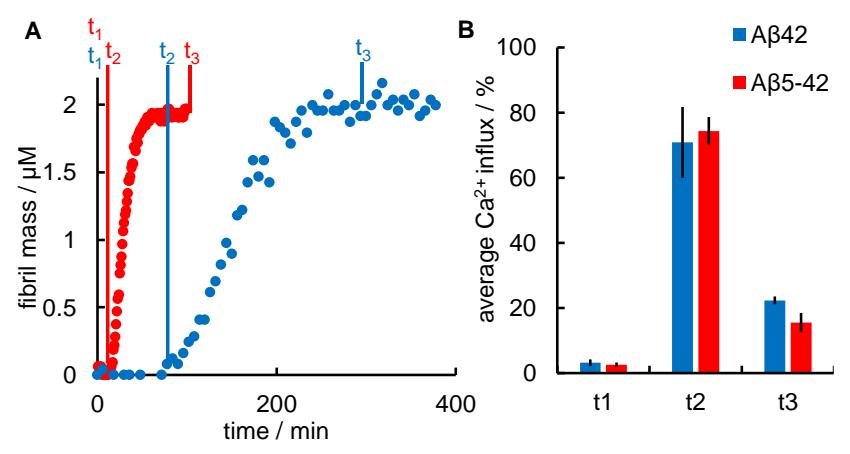

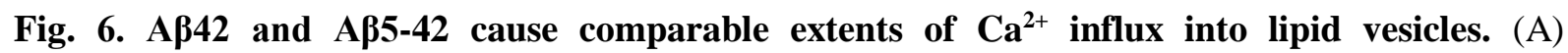
Representative kinetic traces of the formation of amyloid fibrils by A $\beta 42$ (blue) and A $\beta 5-42$. Aliquots were removed from the aggregation reaction at time points corresponding to the start of the aggregation reaction $\left(t_{1}\right)$, the end of the lag phase $\left(t_{2}\right)$ and at the plateau phase $\left(t_{3}\right)$. (B) The measured $\mathrm{Ca}^{2+}$ influx into lipid vesicles caused by the samples removed from the aggregation reaction at $t_{1}, t_{2}$ and $t_{3}$.

\section{Conclusion}

Many N-terminally truncated and extended $\mathrm{A} \beta$ species are present in vivo and the overall aggregation process is influenced by their individual aggregation propensity, as well as by their ability to coaggregate and to enhance the aggregation of the monomeric species of different lengths by catalyzing their nucleation on the fibril surface. N-terminally truncated A $\beta 5-42$ displays an increased aggregation rate compared to full-length $A \beta 42$. The rate constants of primary and secondary nucleation are significantly higher for $\mathrm{A} \beta 5-42$, while the elongation rate constants do not differ significantly between the species. In the case of $\mathrm{A} \beta 5-42$, an increased attachment rate of monomeric peptide to existing fibrils results in an increased coverage of the fibril surface and thus saturation of secondary nucleation at lower concentrations of A $\beta 5-42$ compared to $A \beta 42$. The increased attachment rate is most likely facilitated by the less negative charge of A $35-42$ causing less electrostatic repulsion between monomers and fibrils. An increased frequency of productive molecular encounters for a shorter peptide may also contribute to the increased primary and secondary nucleation rates of $A \beta 5-42$. $A \beta 5-42$ and $A \beta 42$ were found to coaggregate into heteromolecular fibrils. Monomers of both species are able to elongate homomolecular fibrils of each species. Only A $\beta 42$ can act as a catalyzing surface for nucleation of the other species. Importantly, the extent of $\mathrm{Ca}^{2+}$ influx into vesicles and thus the ability to disrupt membranes was found 
to be similar for the $A \beta 5-42$ and $A \beta 42$ species at comparable stages of their aggregation indicating that A $\beta 5-42$ has comparable toxic effects to the full-length form of A $\beta 42$. Noteworthy, the formation of A $\beta 5$ 42 species responsible for membrane disruption is accelerated due to the increased secondary nucleation rate compared to $A \beta 42$, thus the toxic effect emerges more quickly for $A \beta 5-42$.

\section{Materials and Methods}

\section{Expression and purification of $\mathbf{A \beta}$}

The peptides $A \beta 1-42$ and $A \beta 5-42$, with amino acid sequences MDAEFRHDSGYEVHHQKLVFFAED VGSNKGAIIGLMVGGVVIA and MRHDSGYEVHHQKLVFFAEDVGSNKGAIIGLMVGGVVIA, respectively, were expressed and purified essentially as previously described (34). Throughout, A $\beta 42$ refers to $A \beta 42(M 1-42)$ and $A \beta 5-42$ refers to $A \beta(M 5-42)$. For $A \beta 5-42,1.0-1.8 \mathrm{M}$ urea was included in the ion exchange elution buffers. In short, the cells were disrupted by sonication (three times), the pellet dissolved in $8 \mathrm{M}$ urea and purified by ion exchange chromatography on DEAE cellulose in batch format. The sample was diluted to $2 \mathrm{M}$ urea before loading on the resin, and the wash and elution buffer contained 1.8 and $1.6 \mathrm{M}$ urea at $10 \mathrm{mM} \mathrm{NaCl}, 1.4$ and $1.2 \mathrm{M}$ urea at $25 \mathrm{mM} \mathrm{NaCl}$ and $1.0 \mathrm{M}$ urea at 100 $\mathrm{mM} \mathrm{NaCl}$. The eluted protein was passed through hydrosart $30 \mathrm{kDa} \mathrm{Mw}$ cutoff filter, concentrated on 5 $\mathrm{kDa} \mathrm{Mw}$ cutoff filter, and stored as lyophilized aliquots. For aggregation experiments the lyophilized purified $A \beta 42$ and $A \beta 5-42$ were dissolved in $6 \mathrm{M} \mathrm{GuHCl}$ for 30 min and subjected to gel filtration on a Superdex 75 10/300 GL column in degassed $20 \mathrm{mM}$ sodium phosphate buffer, pH 8, with $200 \mu \mathrm{M}$ EDTA and $0.02 \% \mathrm{NaN}_{3}$. The centers of the monomer peaks were collected on ice and the concentrations were determined by absorbance at $280 \mathrm{~nm}$ using $\varepsilon_{280}=1440 \mathrm{Lmol}^{-1} \mathrm{~cm}^{-1}$. The gelfiltration step was undertaken to remove pre-existing aggregates and to exchange the buffer. All chemicals were of analytical grade.

\section{Kinetic assay}

Highly pure recombinant peptides were used to guarantee homogeneous sequence, which enables quantitative analysis of the microscopic steps involved in the aggregation process. To enable kinetic 
analysis of A $\beta 5-42$ the use of recombinant peptide is a prerequisite, however, the requirement of a start codon resulted in addition of a methionine residue at the $\mathrm{N}$-terminus. In practice, this means that the hydrophobic phenylalanine located at position four in the $A \beta 42$ sequence was replaced by another hydrophobic residue.

The aggregation of $A \beta 5-42$ was studied at 17 different monomer concentrations between 0.125 and 5 $\mu \mathrm{M}$, at $37^{\circ} \mathrm{C}$, under quiescent conditions. All samples contained $6 \mu \mathrm{M}$ thioflavin $\mathrm{T}(\mathrm{ThT})$ and were prepared on ice in low-bind Eppendorf tubes (Genuine Axygen Quality, Microtubes, MCT-200-L-C). The aggregation kinetics was measured in Corning 3881, 96-well half-area plates of black polystyrene with clear bottom and PEG coating. Each well was carefully loaded with $80 \mu \mathrm{L}$ peptide solution and the plates were sealed with a plastic film (Corning 3095). The ThT fluorescence was measured using a Fluostar Omega or Fluostar Optima plate reader (BMG Labtech Offenburg, Germany), with the excitation and emission at 440 and $480 \mathrm{~nm}$, respectively. Measurements were undertaken approximately every second minute and studied on three separate occasions with quadruplicate samples for each concentration.

\section{Preseeded kinetic assays}

$\mathrm{A} \beta 42$ and $\mathrm{A} \beta 5-42$ fibrils in $20 \mathrm{mM}$ sodium phosphate buffer, $\mathrm{pH} 8$, with $200 \mu \mathrm{M}$ EDTA and $0.02 \%$ $\mathrm{NaN}_{3}$ were prepared in 96-well half-area plates of black polystyrene with clear bottom and PEG coating by monitoring the fluorescence of the corresponding samples with ThT added. The formed fibrils were used as seeds and added to samples containing $2 \mu \mathrm{M}$ monomeric $\mathrm{A} \beta 42$ or $\mathrm{A} \beta 5-42$, prepared as described above. The seed concentrations ranged between $0.001 \%$ and $10 \%$. Both self-seeding (A $\beta 5-42$ seeds added to $A \beta 5-42$ monomers and $A \beta 42$ seeds added to $A \beta 42$ monomers) and cross-seeding (A $\beta 5-42$ seeds added to $A \beta 42$ monomers and $A \beta 42$ seeds added to $A \beta 5-42$ monomers) were investigated. Measurements were performed on three separate occasions with quadruplicate samples for each concentration.

\section{Coaggregation}


Coaggregation kinetics of $A \beta 42$ and $A \beta 5-42$ were studied at equimolar concentrations of the two proteins ranging from $1 \mu \mathrm{M}$ to $3.5 \mu \mathrm{M}$ of each protein. Kinetic measurements were performed on three separate occasions with quadruplicate samples for each concentration, as described in Kinetic assay.

In order to investigate whether the decrease in signal was due to a decrease in the amount of aggregates present, rather than a change in fluorescence intensity per mole of aggregates, equimolar mixtures of $\mathrm{A} \beta 42$ and $\mathrm{A} \beta 5-42$ at individual concentrations ranging from 1-3.5 $\mu \mathrm{M}$ were aggregated at $37{ }^{\circ} \mathrm{C}$ under quiescent conditions in the absence of ThT and after aggregation the samples were centrifuged at 13000 $\mathrm{rpm}$ for $1 \mathrm{~min}$ and $10 \mu \mathrm{l}$ were taken from the top of the sample to avoid fibrils. Monomeric samples kept on ice during the fibrillation were treated the same way. Samples were analyzed on a Novex 4-20\% Tris/tricine protein gel (Thermo Fischer Scientific) using as Mw standard a Spectra ${ }^{\mathrm{TM}}$ Multicolor Low Range protein ladder (Thermo Fischer Scientific).

\section{Kinetic Analysis}

Global analysis of A $\beta 5-42$ aggregation kinetics to extract the rate constants for primary nucleation, secondary nucleation and elongation was performed using the online Amylofit platform (23). Three repeats of A 55-42 aggregation experiments were uploaded, normalized and fitted. The integrated rate law for the normalized aggregate concentration is

$$
\frac{[M]}{[M]_{\infty}}=1-\left(1-\frac{[M]_{0}}{[M]_{\infty}}\right) e^{-k_{\infty} t} *\left(\frac{B_{-}+C_{+} e^{\kappa t}}{B_{+}+C_{+} e^{\kappa t}} * \frac{B_{+}+C_{+}}{B_{-}+C_{+}}\right) \frac{k_{\infty}}{\kappa^{k_{\infty}}}
$$

where the parameters are defined by

$$
\begin{aligned}
& \kappa=\sqrt{2[m]_{0} k_{+} \frac{[m]_{0}^{n_{2}} k_{2}}{1+[m]_{0}^{n_{2}} / K_{M}}} \\
& \lambda=\sqrt{2 k_{+} k_{n}[m]_{0}^{n_{c}}} \\
& C_{ \pm}=\frac{k_{+}[P]_{0}}{\kappa} \pm \frac{k_{+}[M]_{0}}{2[m]_{0} k_{+}} \pm \frac{\lambda^{2}}{2 \kappa^{2}}
\end{aligned}
$$




$$
\begin{aligned}
& k_{\infty}=2 k_{+}[P]_{\infty} \\
& \bar{k}_{\infty}=\sqrt{k_{\infty}^{2}-2 C_{+} C_{-} \kappa^{2}} \\
& B_{ \pm}=\frac{k_{\infty} \pm \bar{k}_{\infty}}{2 \kappa}
\end{aligned}
$$

where $[\mathrm{m}]_{0}$ is the initial monomer concentration, $[\mathrm{P}]_{0}$ is aggregate number at the start of the reaction, $[\mathrm{P}]_{\infty}$ is the aggregate number at equilibrium, that is, after reaction completion, $[\mathrm{M}]_{0}$ is the mass concentration of fibrils at the start of the reaction and $[\mathrm{M}]_{\infty}$ is the mass concentration of fibrils at equilibrium. $k_{\mathrm{n}}, k_{2}, k_{+}$are the rate constants for primary nucleation, secondary nucleation and elongation respectively. $K_{M}$ is the saturation constant for secondary nucleation and $n_{2}$ and $n_{c}$ are the monomer scalings of primary and secondary nucleation. $\mathrm{n}_{\mathrm{c}}=\mathrm{n}_{2}=2$ was used for fitting of AB5-42 aggregation kinetics.

\section{Estimation of the elongation rate constant}

The elongation rate constant was estimated by adding $2 \mu \mathrm{M}$ preformed $\mathrm{A} \beta 5-42$ fibrils to varying concentrations of A $\beta 5-42$ monomers. The initial gradients of the kinetic profiles are given by $\mathrm{dM} / \mathrm{dt}=$ $2 \mathrm{k}_{+} \mathrm{m}_{0} \mathrm{P}_{0}$, where $\mathrm{M}$ is the fibril mass concentration and $\mathrm{P}_{0}$ is the initial fibril number concentration, and by plotting the initial gradient vs $\mathrm{m}_{0}$ the slope gives $\mathrm{k}_{+} \mathrm{P}_{0}$. The curvature of this plot also give insight to the saturation of the elongation rate. The number of fibrils was estimated by measuring the average end to end distance and width of 116 individual A $\beta 5-42$ fibrils from cryo-TEM images using ImageJ. The average length of fibrils was $320 \pm 19 \mathrm{~nm}$ and the average width was $8.4 \pm 2.5 \mathrm{~nm}$. Assuming that the average protein density is $1.3 \mathrm{~g} / \mathrm{mL}$ and the molecular weight is $4.18 \mathrm{kDa}$ per $\mathrm{A} \beta 5-42$ peptide, the average number of monomers per fibril could be estimated to 3676. Since the average seed mass concentration, $\mathrm{M}_{0}$, was known $\mathrm{P}_{0}$ could be estimated. From the initial gradient of the seeded experiments $2 \mathrm{k}_{+} \mathrm{P}_{0}$ was approximately $2.4 \cdot 10^{-3} \mathrm{~s}^{-1}$. Together with the number of monomers per fibril the elongation rate constant was estimated to approximately $2.2 \cdot 10^{6} \mathrm{M}^{-1} \mathrm{~s}^{-1}$.

\section{Cryo-TEM}


Monomeric A $\beta 42$ and A $\beta 5-42$ were prepared as described above. Five different conditions were studied using cryo-TEM: A $\beta 5-42$, coaggregation of $A \beta 42$ and $A \beta 5-42$, cross-seeding of $A \beta 42$ and $A \beta 5-42$ (with either $A \beta 42$ or $A \beta 5-42$ seeds) and self-seeding of $A \beta 5-42$ and $A \beta 42$. The total $A \beta$ concentration was 10 $\mu \mathrm{M}$ and aggregation experiments were performed with and without $\mathrm{ThT}$, at $37{ }^{\circ} \mathrm{C}$, under quiescent conditions. A sample without ThT was taken when the aggregation reaction reached the plateau value and $5 \mu \mathrm{L}$ were loaded to a thin film on a lacey carbon filmed copper grid, $<300 \mathrm{~nm}$ thick, and flash frozen in liquid ethane at $-180{ }^{\circ} \mathrm{C}$ and stored under liquid nitrogen. Images were acquired using a 120 kV electron microscope (Philips CM120 BioTWIN Cryo).

\section{$\mathrm{Ca}^{2+}$ influx assay}

The single vesicle assay was carried out as previously described (30) and in the Supporting Information. Shortly, vesicles, with a mean diameter of $200 \mathrm{~nm}$, filled with Cal-520 were prepared by freeze-thawing cycles followed by extrusion and gel filtration before they were tethered to a microscopy cover slide through neutravidin biotin linkage. Monomeric A $\beta 42$ and A $\beta 5-42$ were isolated and aggregated at 37 ${ }^{\circ} \mathrm{C}$ under quiescent conditions. Samples for the $\mathrm{Ca}^{2+}$ influx assay were taken before incubation, at the end of the lag phase and at the plateau phase. For each sample (total internal reflection fluorescence microscopy) TIRFM images were acquired under three conditions: in the presence of $\mathrm{Ca}^{2+}$ buffer, after the addition of $\mathrm{A} \beta$ sample and after the addition of an ionophore. The fluorescence intensity of at least 700 vesicles per sample were analysed using Fiji (35) and the relative influx of $\mathrm{Ca}^{2+}$ caused by the $\mathrm{A} \beta$ peptides was determined. Finally, the average $\mathrm{Ca}^{2+}$ influx was calculated by averaging over the $\mathrm{Ca}^{2+}$ influx into individual vesicles. The reported values are mean values from three independent measurements.

\section{Acknowledgement}

We thank Gunnel Karlsson, Lund University, for excellent help with cryo-TEM.

This work was supported by the European Research Council (SL, HZ), the Swedish Research Council (SL, HZ, KB), Alzheimerfonden (EP, KB, SL), the Centre for Misfolding Diseases (GM, PF, CMD, 
TPJK), Sidney Sussex College Cambridge (GM), Boehringer Ingelheim Fonds (PF), Studienstiftung des deutschen Volkes (PF), Marie Curie individual fellowship (SD), UK Biotechnology and Biochemical Sciences Research Council (CMD), the Royal Society (DK), the Torsten Söderberg Foundation at the Royal Swedish Academy of Science (KB), the Swedish Brain Foundation (KB), Stiftelsen för Gamla Tjänarinnor (EP). HZ is a Wallenberg Academy Fellow.

\section{Conflict of Interest}

KB has served as a consultant or at advisory boards for Alzheon, BioArctic, Biogen, Eli Lilly, Fujirebio Europe, IBL International, Merck, Novartis, Pfizer, and Roche Diagnostics, and is a co-founder of Brain Biomarker Solutions in Gothenburg AB, a GU Venture-based platform company at the University of Gothenburg, all unrelated to the work presented in the current paper. The other authors declare no conflicts of interest.

\section{Author Contributions:}

Designed study: SL, TW, PF, SD, CJRD, HZ, KB, EP

Performed experiments: TW, PF, SD, CJRD

Contributed reagents and tools: $\mathrm{BF}, \mathrm{CJRD}, \mathrm{HZ}$

Analyzed data: TW, GM, PF, SD, DK, TPJK, CD

Wrote the paper with input from other authors: TW, GM, SL

\section{Supporting Information:}

SI Material and Methods

ThT controls

$\mathrm{Ca}^{2+}$ influx assay

SI Figures

Fig. S1. Effect of ThT on aggregation kinetics

Fig. S2. Global analysis using the Amylofit platform

Fig. S3. Global analysis by alternate models

Fig. S4. Non-normalized data from seeding experiments

Fig. S5. Cross-seeding of $A \beta 5-42$ monomers and $A \beta 42$ seeds

Fig. S6 Fits of $A \beta 5-42$ aggregation kinetics in the presence of $A \beta 42$ seeds.

Fig. S7 Cross-seeding of A $\beta 5-42$ monomers and $A \beta 42$ seeds.

Fig. S8. Electrophoresis analysis of remaining A $\beta 5-42$ and $A \beta 42$ monomers after coaggregation 
Fig. S9. TIRFM images

Table S1. Combined rate constants for $1-5 \mu \mathrm{M} A \beta$ 


\section{References}

1. Masters CL, Bateman R, Blennow K, Rowe CC, Sperling RA, \& Cummings JL (2015) Alzheimer's disease. Nat Rev Dis Primers 1:15056.

2. Hardy JA \& Higgins GA (1992) Alzheimer's disease: the amyloid cascade hypothesis. Science 256(5054):184-185.

3. Wildburger NC, Esparza TJ, LeDuc RD, Fellers RT, Thomas PM, Cairns NJ, Kelleher NL, Bateman RJ, \& Brody DL (2017) Diversity of Amyloid-beta Proteoforms in the Alzheimer's Disease Brain. Sci. Rep. 7(1):9520.

4. Steiner H, Fluhrer R, \& Haass C (2008) Intramembrane proteolysis by gamma-secretase. J. Biol. Chem. 283(44):29627-29631.

5. Vassar R (2014) BACE1 inhibitor drugs in clinical trials for Alzheimer's disease. Alzheimers Res. Ther. 6(9):89.

6. Mattsson N, Rajendran L, Zetterberg H, Gustavsson M, Andreasson U, Olsson M, Brinkmalm G, Lundkvist J, Jacobson LH, Perrot L, Neumann U, Borghys H, Mercken M, Dhuyvetter D, Jeppsson F, Blennow K, \& Portelius E (2012) BACE1 inhibition induces a specific cerebrospinal fluid beta-amyloid pattern that identifies drug effects in the central nervous system. PLoS One 7(2):e31084.

7. Portelius E, Dean RA, Andreasson U, Mattsson N, Westerlund A, Olsson M, Demattos RB, Racke MM, Zetterberg H, May PC, \& Blennow K (2014) beta-site amyloid precursor proteincleaving enzyme 1(BACE1) inhibitor treatment induces Abeta5-X peptides through alternative amyloid precursor protein cleavage. Alzheimers Res. Ther. 6(5-8):75.

8. Meisl G, Yang X, Hellstrand E, Frohm B, Kirkegaard JB, Cohen SI, Dobson CM, Linse S, \& Knowles TP (2014) Differences in nucleation behavior underlie the contrasting aggregation kinetics of the Abeta40 and Abeta42 peptides. Proc. Natl. Acad. Sci. U. S. A. 111(26):93849389.

9. Szczepankiewicz O, Linse B, Meisl G, Thulin E, Frohm B, Sala Frigerio C, Colvin MT, Jacavone AC, Griffin RG, Knowles T, Walsh DM, \& Linse S (2015) N-Terminal Extensions Retard Abeta42 Fibril Formation but Allow Cross-Seeding and Coaggregation with Abeta42. J. Am. Chem. Soc. 137(46):14673-14685.

10. Hellstrand E, Boland B, Walsh DM, \& Linse S (2010) Amyloid beta-protein aggregation produces highly reproducible kinetic data and occurs by a two-phase process. ACS Chem. Neurosci. 1(1):13-18.

11. Cohen SI, Vendruscolo M, Dobson CM, \& Knowles TP (2011) Nucleated polymerization with secondary pathways. II. Determination of self-consistent solutions to growth processes described by non-linear master equations. J. Chem. Phys. 135(6):065106.

12. Cohen SI, Linse S, Luheshi LM, Hellstrand E, White DA, Rajah L, Otzen DE, Vendruscolo M, Dobson CM, \& Knowles TP (2013) Proliferation of amyloid-beta42 aggregates occurs through a secondary nucleation mechanism. Proc. Natl. Acad. Sci. U. S. A. 110(24):9758-9763.

13. Yang X, Meisl G, Frohm B, Thulin E, Knowles TPJ, \& Linse S (2018) On the role of sidechain size and charge in the aggregation of Abeta42 with familial mutations. Proc. Natl. Acad. Sci. U. S. A. 115(26):E5849-E5858.

14. Meisl G, Yang X, Dobson CM, Linse S, \& Knowles TPJ (2017) Modulation of electrostatic interactions to reveal a reaction network unifying the aggregation behaviour of the Abeta42 peptide and its variants. Chem. Sci. 8(6):4352-4362.

15. Pike CJ, Overman MJ, \& Cotman CW (1995) Amino-terminal deletions enhance aggregation of beta-amyloid peptides in vitro. J. Biol. Chem. 270(41):23895-23898.

16. Cukalevski R, Yang X, Meisl G, Weininger U, Bernfur K, Frohm B, Knowles TPJ, \& Linse S (2015) The Abeta40 and Abeta42 peptides self-assemble into separate homomolecular fibrils in binary mixtures but cross-react during primary nucleation. Chem. Sci. 6(7):4215-4233.

17. Dammers C, Schwarten M, Buell AK, \& Willbold D (2017) Pyroglutamate-modified Abeta(342) affects aggregation kinetics of Abeta(1-42) by accelerating primary and secondary pathways. Chem. Sci. 8(7):4996-5004. 
18. Iljina M, Garcia GA, Dear AJ, Flint J, Narayan P, Michaels TC, Dobson CM, Frenkel D, Knowles TP, \& Klenerman D (2016) Quantitative analysis of co-oligomer formation by amyloid-beta peptide isoforms. Sci. Rep. 6:28658.

19. Egan MF, Kost J, Tariot PN, Aisen PS, Cummings JL, Vellas B, Sur C, Mukai Y, Voss T, Furtek C, Mahoney E, Harper Mozley L, Vandenberghe R, Mo Y, \& Michelson D (2018) Randomized Trial of Verubecestat for Mild-to-Moderate Alzheimer's Disease. N. Engl. J. Med. 378(18):1691-1703.

20. May PC, Dean RA, Lowe SL, Martenyi F, Sheehan SM, Boggs LN, Monk SA, Mathes BM, Mergott DJ, Watson BM, Stout SL, Timm DE, Smith Labell E, Gonzales CR, Nakano M, Jhee SS, Yen M, Ereshefsky L, Lindstrom TD, Calligaro DO, Cocke PJ, Greg Hall D, Friedrich S, Citron M, \& Audia JE (2011) Robust central reduction of amyloid-beta in humans with an orally available, non-peptidic beta-secretase inhibitor. J. Neurosci. 31(46):16507-16516.

21. Portelius E, Olsson M, Brinkmalm G, Ruetschi U, Mattsson N, Andreasson U, Gobom J, Brinkmalm A, Holtta M, Blennow K, \& Zetterberg H (2013) Mass spectrometric characterization of amyloid-beta species in the 7PA2 cell model of Alzheimer's disease. $J$. Alzheimers Dis. 33(1):85-93.

22. Meisl G, Yang X, Frohm B, Knowles TP, \& Linse S (2016) Quantitative analysis of intrinsic and extrinsic factors in the aggregation mechanism of Alzheimer-associated Abeta-peptide. Sci. Rep. 6:18728.

23. Meisl G, Kirkegaard JB, Arosio P, Michaels TC, Vendruscolo M, Dobson CM, Linse S, \& Knowles TP (2016) Molecular mechanisms of protein aggregation from global fitting of kinetic models. Nat. Protoc. 11(2):252-272.

24. Flagmeier P, Meisl G, Vendruscolo M, Knowles TP, Dobson CM, Buell AK, \& Galvagnion C (2016) Mutations associated with familial Parkinson's disease alter the initiation and amplification steps of alpha-synuclein aggregation. Proc. Natl. Acad. Sci. U. S. A. 113(37):10328-10333.

25. Welzel AT, Maggio JE, Shankar GM, Walker DE, Ostaszewski BL, Li S, Klyubin I, Rowan MJ, Seubert P, Walsh DM, \& Selkoe DJ (2014) Secreted amyloid beta-proteins in a cell culture model include N-terminally extended peptides that impair synaptic plasticity. Biochemistry 53(24):3908-3921.

26. Soto C (2003) Unfolding the role of protein misfolding in neurodegenerative diseases. Nat. Rev. Neurosci. 4(1):49-60.

27. Andreasen M, Lorenzen N, \& Otzen D (2015) Interactions between misfolded protein oligomers and membranes: A central topic in neurodegenerative diseases? Biochim. Biophys. Acta 1848(9):1897-1907.

28. Serra-Batiste M, Ninot-Pedrosa M, Bayoumi M, Gairi M, Maglia G, \& Carulla N (2016) Abeta42 assembles into specific beta-barrel pore-forming oligomers in membrane-mimicking environments. Proc. Natl. Acad. Sci. U. S. A. 113(39):10866-10871.

29. Benilova I, Karran E, \& De Strooper B (2012) The toxic Abeta oligomer and Alzheimer's disease: an emperor in need of clothes. Nat. Neurosci. 15(3):349-357.

30. Flagmeier P, De S, Wirthensohn DC, Lee SF, Vincke C, Muyldermans S, Knowles TPJ, Gandhi S, Dobson CM, \& Klenerman D (2017) Ultrasensitive Measurement of Ca(2+) Influx into Lipid Vesicles Induced by Protein Aggregates. Angew. Chem. Int. Ed. Engl. 56(27):7750-7754.

31. Bitan G, Kirkitadze MD, Lomakin A, Vollers SS, Benedek GB, \& Teplow DB (2003) Amyloid beta -protein (Abeta) assembly: Abeta 40 and Abeta 42 oligomerize through distinct pathways. Proc. Natl. Acad. Sci. U. S. A. 100(1):330-335.

32. Bitan G, Vollers SS, \& Teplow DB (2003) Elucidation of primary structure elements controlling early amyloid beta-protein oligomerization. J. Biol. Chem. 278(37):34882-34889.

33. Urbanc B, Cruz L, Yun S, Buldyrev SV, Bitan G, Teplow DB, \& Stanley HE (2004) In silico study of amyloid beta-protein folding and oligomerization. Proc. Natl. Acad. Sci. U. S. A. 101(50):17345-17350.

34. Walsh DM, Thulin E, Minogue AM, Gustavsson N, Pang E, Teplow DB, \& Linse S (2009) A facile method for expression and purification of the Alzheimer's disease-associated amyloid beta-peptide. FEBS J. 276(5):1266-1281. 
35. Schindelin J, Arganda-Carreras I, Frise E, Kaynig V, Longair M, Pietzsch T, Preibisch S, Rueden C, Saalfeld S, Schmid B, Tinevez JY, White DJ, Hartenstein V, Eliceiri K, Tomancak P, \& Cardona A (2012) Fiji: an open-source platform for biological-image analysis. Nat. Methods 9(7):676-682. 
Table of contents graphics

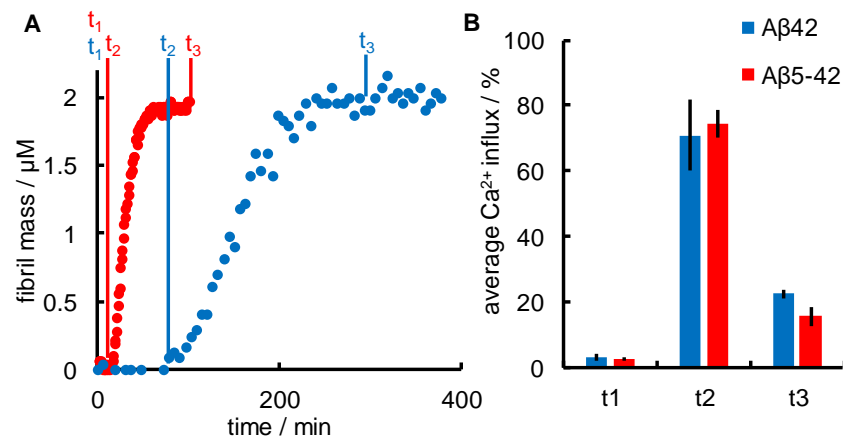

